\title{
A 2-Dimensional Numerical Model of the Quasi-Biennial Oscillation:
}

\section{Part I}

\author{
By Masaaki Takahashi \\ Department of Physics, Faculty of Science, Kyushu University, Fukuoka 812, Japan \\ (Manuscript received 16 January 1987, in revised form 17 June 1987)
}

\begin{abstract}
We conduct numerical experiments of the quasi-biennial oscillation (QBO) using a 2-dimensional model. An oscillation with period of about 600 days is obtained. The simulated oscillation is very similar to the observed QBO in many respects:

(1) The faster downward propagation of the westerly wind than that of the easterly is obtained.

(2) The westerly wind appears at first on the equator but the easterly spreads from the mid-latitude region.

(3) The meridional extent of the westerly wind at the initial onset in the upper layer is very narrow. We analyze the effects of wave transience, change of zonal phase velocity by wave self-acceleration mechanism and wave breaking in the model. The effects except wave self-acceleration are crucial in the present model.

The dependence of the results on the magnitude of the dissipation coefficients is examined. We have conducted some numerical experiments with different initial conditions. However, the same steady state solution is always obtained when the magnitude of the dissipation is large. In this case, it seems that no multiple equilibrium exists in spite of the nonlinearity of the system.
\end{abstract}

\section{Introduction}

It is well known that there is the quasibiennial oscillation (QBO) in the equatorial lower stratosphere (cf. Reed et al., 1961; Nastrom and Belmont, 1975; Hamilton, 1984; Dunkerton and Delisi, 1985). The basic mechanism of the QBO is also well known since the two companion works by Lindzen and Holton (1968) and Holton and Lindzen (1972) were done. The QBO is basically explained by the wave momentum deposition in the zonal mean flow by upward propagating equatorial waves with dissipation: mean westerlies are driven by equatorial Kelvin waves (cf. Wallace and Kousky, 1968) and mean easterlies are driven by mixed Rossby-gravity waves (cf. Yanai and Maruyama, 1966).

Plumb (1977) has elucidated the mechanism of the QBO. He has shown that the increase of Newtonian cooling coefficient with height in the

(C1987, Meteorological Society of Japan stratosphere is not crucial to the mechanism and the strarospheric semi-annual oscillation as a trigger for phase change of the QBO is irrelevant. $\mathrm{He}$ has also noted that momentum diffusion in the lower stratosphere may be of crucial importance. Further he has demonstrated an oscillation like the QBO in a laboratory experiment (Plumb and McEwan, 1978).

Recently, 1-dimensional models of the QBO have been developed by some authors (Dunkerton, 1981; Tanaka and Yoshizawa, 1985, 1987). Dunkerton suggested that the primary cause of the quasi-biennial oscillation is wave transience. Tanaka and Yoshizawa dealt with the effects of the change of the zonal phase velocity of the wave (the self-acceleration) and/or of wave breaking together with the wave transience under the WKB approximation of the wave. They mentioned that these effects are crucial to the period and structure of the QBO.

The mechanism of the QBO has been basically explained by 1-dimensional (vertical) model. 
But one of the characteristics of the QBO, i.e., the faster downward propagation of the westerly wind than that of the easterly has not been simulated by these models. Further the real atmospheric QBO has a vertical and meridional structure (cf. Wallace, 1973).

2 -dimensional models have been presented by Plumb and Bell (1982; denoted hereafter by PB) and Dunkerton (1985; denoted hereafter by D). The PB model assumes that two waves (Kelvin wave and mixed Rossby-gravity wave) are steady. The steady waves are solved explicitly by the finite difference method at each time step (1 day). They showed that the downward propagation of the westerly wind is faster than that of the easterly. This result is due to the advection of the mean zonal flow by the downward (upward) Lagrangian-mean vertical velocity over the equator when the westerly (easterly) shear region is present. This situation comes from the thermal wind balance and the Lagrangian-mean thermodynamic equation. But the amplitude of mean zonal wind oscillation is too small (about $8 \mathrm{~m} \mathrm{~s}^{-1}$ ) in the PB model. On the other hand, the D model has obtained a realistic large amplitude of the oscillation. The faster downward propagation of the westerly than that of the easterly is obtained in his model too. He also assumed that waves are steady. But wave amplitudes and acceleration by two waves have been estimated by the WKB approximation.

The wave has not been solved explicitly in the previous models of the QBO except the PB model. Almost all models have used the so-called WKB approximation about the wave. The mean flow acceleration due to the wave has been also estimated by the WKB approximation. On the other hand, Holton has attempted to integrate a simple but expensive primitive equation model in the presence of the two equatorial waves, and has not obtained a QBO like solution but a steady state solution (cf. Holton, 1979; Dunkerton, 1985).

General circulation models have not yet reproduced a QBO (cf. Mahlman and Umscheid, 1984). The magnitude of the dissipation coefficients in the general circulation models seems to be too large to obtain a QBO like oscillation as mentioned by Plumb (1984). A steady solution by Holton also might be due to large dissipation coefficients in his model. Another reason why the QBO could not be obtained in the general circulation models may be the coarse vertical resolution (cf. Plumb, 1984).

In the present paper, we conduct numerical experiments of the QBO using a 2-dimensional model. The model is the grid model on an equatorial beta-plane in the meridional and vertical direction. Concerning the zonal direction, only the zonal mean (zonal wavenumber $s=0)$ motion, an $s=1$ Kelvin wave and an $s=4$ mixed Rossby-gravity wave are solved explicitly under the so-called quasi-nonlinear condition: only the terms expressing the interaction between each wave and mean flow are considered and the wave-wave interaction is neglected. Other assumptions used by previous models (for example, the steady wave assumption and/or the WKB approximation) are not included.

Section 2 concerns the model description. Section 3 shows the results and comparison with the observed QBO. In section 4, we analyze the effects of wave transience, self-acceleration of the zonal phase velocity of the wave and the wave breaking in the present model, in order to test the hypotheses presented by the recently developed 1-dimensional models. In section 5, we examine the dependence of the results on the magnitude of the dissipation coefficients. Section 6 is devoted to concluding remarks.

\section{The basic equations and the model}

The model is based on the primitive equations on the equatorial beta-plane with a $\log$-pressure vertical coordinate defined as $z=-H \ln \left(p / p_{s}\right)$, where $H(=6 \mathrm{~km})$ is a constant mean scale height and $p_{s}$ a standard pressure. The basic state is assumed to be isothermal atmosphere at rest. All dependent variables are split into zonal mean parts (denoted by overbars) and two wave components: a Kelvin wave $(s=a k=1)$ and a mixed Rossby-gravity wave $(s=4)$, where $k$ and $s$ are dimensional and non-dimensional zonal wavenumber, respectively and $a$ means the earth's radius. In the present study the vertical eddy heat flux term is neglected (cf. PB) and wave momentum fluxes in the mean meridional flow equation are also neglected (see eq. (2-7)). The equations for waves and zonal mean components are as follows. 
Wave equation for the Kelvin wave and the mixed Rossby-gravity wave;

$$
\begin{aligned}
& \left(\frac{\partial}{\partial t}+\bar{u} \frac{\partial}{\partial x}\right) u+v \frac{\partial \bar{u}}{\partial y}+w \frac{\partial \bar{u}}{\partial z}-\beta y v \\
& =-\frac{\partial \phi}{\partial x}-\alpha u+\nu \frac{\partial^{2} u}{\partial z^{2}}+d \nabla_{H}^{2} u, \\
& \left(\frac{\partial}{\partial t}+\bar{u} \frac{\partial}{\partial x}\right) v+\beta y u \\
& =-\frac{\partial \phi}{\partial y}-\alpha v+\nu \frac{\partial^{2} v}{\partial z^{2}}+d \nabla_{H}^{2} v, \\
& \left(\frac{\partial}{\partial t}+\bar{u} \frac{\partial}{\partial x}\right) \frac{\partial \phi}{\partial z}+v \frac{\partial}{\partial y} \frac{\partial \bar{\phi}}{\partial z}+N^{2} w \\
& \quad=-\alpha, \frac{\partial \phi}{\partial z}+\kappa \frac{\partial^{2}}{\partial z^{2}} \phi_{z}+d V_{H}^{2} \phi_{z}, \\
& \frac{\partial u}{\partial x}+\frac{\partial v}{\partial y}+\frac{1}{\rho} \frac{\partial}{\partial z} \rho w=0, \\
& \frac{\partial \phi}{\partial z}=R T / H .
\end{aligned}
$$

Zonal mean component;

$$
\begin{aligned}
& \frac{\partial \bar{u}}{\partial t}+\bar{v} \frac{\partial \bar{u}}{\partial y}+\bar{w} \frac{\partial \bar{u}}{\partial z}-\beta y \bar{v} \\
& =-\frac{\partial}{\partial y}(\overline{u v})-\frac{\partial}{\rho \partial z}(\rho \overline{u w})+\nu \frac{\partial^{2} \bar{u}}{\partial z^{2}}+d \frac{\partial^{2} \bar{u}}{\partial y^{2}},
\end{aligned}
$$

$$
\frac{\partial \bar{v}}{\partial t}+\beta y \bar{u}=-\frac{\partial \bar{\phi}}{\partial y}+\nu \frac{\partial^{2} \bar{v}}{\partial z^{2}}+d \frac{\partial^{2} \bar{v}}{\partial y^{2}},
$$

$\frac{\partial}{\partial t} \bar{\phi}_{z}+\bar{v} \frac{\partial}{\partial y} \bar{\phi}_{z}+\bar{w} \frac{\partial}{\partial z} \bar{\phi}_{z}+N^{2} \bar{w}$

$=-\frac{\partial}{\partial y}\left(\overline{v \phi}_{z}\right)-\alpha_{N} \frac{\partial \bar{\phi}}{\partial z}+\kappa \frac{\partial^{2}}{\partial z^{2}} \bar{\phi}_{z}+d \frac{\partial^{2}}{\partial y^{2}} \bar{\phi}_{z}$,

$$
\frac{\partial \bar{v}}{\partial y}+\frac{1}{\rho} \frac{\partial}{\partial z}(\rho \bar{w})=0,
$$

$$
\frac{\partial \bar{\phi}}{\partial z}=R \bar{T} / H
$$

where $\beta\left(=2.29 \times 10^{-11} \mathrm{~s}^{-1} \cdot \mathrm{m}^{-1}\right)$ is the Rossby parameter, $N^{2}\left(=5 \times 10^{-4} \mathrm{~s}^{-2}\right)$ is the squared buoyancy frequency, $\alpha$ is the Rayleigh friction coefficient, $\alpha_{N}$ is the Newtonian cooling coefficient,$\nu$ is the vertical eddy viscosity coefficient, $\kappa$ is the vertical eddy conductivity coefficient, $d$ is the horizontal eddy diffusion coefficient and $\nabla_{H}^{2}$ is the horizontal Laplacian. Other notations are standard ones as in Holton (1975).

The wave momentum and heat fluxes in eqs. (2-6) and (2-8) consist of the Kelvin wave and the mixed Rossby-gravity wave components, respectively. In the present model, the Rayleigh friction is applied only for the wave disturbances.

The simulation domain has its lower boundary at $z=17 \mathrm{~km}$ and its upper boundary at $z=$ $33 \mathrm{~km}$. It is bounded laterally by the equator and $y=4500 \mathrm{~km}$. We assume the symmetry about the equator concerning the Kelvin wave and the zonal mean flow, and anti-symmetry about the equator concerning the mixed Rossby-gravity wave.

The bottom boundary condition is as follows.

$$
\begin{aligned}
& \bar{u}=\bar{v}=\bar{T}=\bar{\phi}=0, \\
& u=v=T=0, \\
& \phi_{k}=3.00 \times 10^{2} \exp \left(-\beta y^{2} / 2 c_{k}\right) \mathrm{m}^{2} \mathrm{~s}^{-2}, \\
& \phi_{R G}=\frac{2.14 \times 10^{2} y \exp \left(-\beta 1 \mathrm{y}^{2} / 2 N\right)}{\sqrt{N / \beta 1}} \mathrm{~m}^{2} \mathrm{~s}^{-2}, \\
& \text { at } z=17 \mathrm{~km},
\end{aligned}
$$

where $c_{k}$ is the phase velocity of the Kelvin wave, $1=N(\beta-\omega k) / \omega^{2}, \omega$ is the frequency of the mixed Rossby-gravity wave, $\phi_{k}$ and $\phi_{R G}$ denote the prescribed geopotentials of the Kelvin and the mixed Rossby-gravity waves, respectively. These values are chosen to give the same plus and minus value of the meridionally integrated upward momentum flux $\int_{0}^{\infty} \overline{\phi w} / c d y$ $=1.07 \times 10^{4} \mathrm{~m}^{3} \mathrm{~s}^{-2}$ for each wave. This value corresponds to $\overline{u w}=1.05 \times 10^{-2} \mathrm{~m}^{2} \mathrm{~s}^{-2}$ approximately (not exactly because of the boundary condition) for Kelvin wave at the equator. This is nearly equal to twice of the momentum flux of Holton-Lindzen model and nearly equal to that of PB. It is noted that this value of the geopotential seems to be consistent with the observational value (cf. Wallace, 1973).

The top boundary condition is 


$$
\begin{aligned}
& \frac{\partial \bar{u}}{\partial z}=\frac{\partial \bar{v}}{\partial z}=\frac{\partial \bar{T}}{\partial z}=\bar{w}=0, \\
& \frac{\partial u}{\partial z}=\frac{\partial v}{\partial z}=\frac{\partial T}{\partial z}=w=0, \\
& \text { at } \quad z=33 \mathrm{~km},
\end{aligned}
$$

The side boundary condition is as follows.

$$
\begin{aligned}
& \bar{u}=\bar{v}=\bar{T}=0, \\
& u=v=T=0,
\end{aligned}
$$

$$
\text { at } y=4500 \mathrm{~km} \text {. }
$$

The values of dissipation coefficients are assumed as

$$
\begin{aligned}
\nu= & \kappa=0.04 \mathrm{~m}^{2} \mathrm{~s}^{-1}, \\
\alpha= & \alpha_{N}=5 \times 10^{-7} \\
& +1 \times 10^{-5} \exp ((z-33 \mathrm{~km}) / 2 \mathrm{~km}) \mathrm{s}^{-1},
\end{aligned}
$$

$$
d=5 \times 10^{3} \mathrm{~m}^{2} \mathrm{~s}^{-1} .
$$

In section 5 we will investigate the cases of different values of $\nu$ and $\alpha$. Concerning the value of the horizontal diffusion coefficient $d$, we use the same value in all cases of the present model. The second term of the right hand side of the Rayleigh friction coefficient shows the sponge layer to prevent a spurious reflection from the top boundary.

It is noted that the value of vertical eddy viscosity coefficient $\nu$ in the present model is one order smaller than that used in 1-dimensional models $\left(0.3 \mathrm{~m}^{2} \mathrm{~s}^{-1}\right)$. When we use large value of $\nu$, a steady state solution is obtained. Thus, we must use this small value. This result has been already mentioned in $D$. See also section 5 .

The value of the Newtonian cooling coefficient $\alpha_{N}$ corresponds to the damping time scale of 23 days, which is consistent with Dickinson's (1973) parameterization of the long wave radiation.

The time evolution is integrated by using the leap-frog scheme. Initial condition is motionless in almost all numerical experiments. The meridional and vertical grid sizes are $300 \mathrm{~km}$ and $500 \mathrm{~m}$, respectively. The time increment $\Delta t$ is 10 minutes.

The zonal phase velocities of the Kelvin wave and the mixed Rossby-gravity wave forced at the bottom boundary are assumed as,

$$
c_{k}=30 \mathrm{~m} \mathrm{~s}^{-1}, \quad \text { for Kelvin wave, }
$$

$$
\begin{array}{ll}
c_{R G}=-30 \mathrm{~m} \mathrm{~s}^{-1}, & \text { for mixed Rossby- } \\
\text { gravity wave. }
\end{array}
$$

\section{Results and comparison with observations}

Fig. 1 shows the time-height section of mean zonal wind at $y=150 \mathrm{~km}$ (near the equator because of the grid point). The oscillation period is about 600 days. The mean period of the observed QBO is about 780 days. But the period of 600 days is within the observed period of QBO (cf. Plumb, 1984). It is noted that the downward propagation of the westerly wind is faster than that of the easterly in the middle layer. This is in good agreement with the ob-

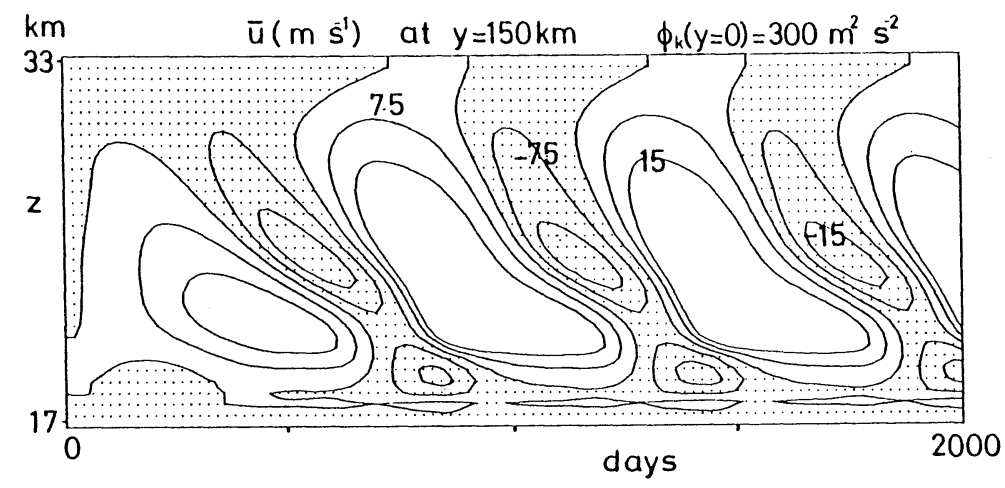

Fig. 1 Time-height section of the mean zonal wind at $y=150 \mathrm{~km}$. Dotted regions indicate negative anomaly. 
served $\mathrm{QBO}$ and the oscillation of the 2-dimensional models by $P B$ and $D$. The easterly wind at the higher levels lasts longer than that at the lower levels. On the other hand, the westerly wind at the lower levels lasts longer than that at the higher levels. This result is also consistent with the observation (cf. Naujokat, 1986).

Easterly winds always exist in the lower layer (near the bottom boundary). This result is different from those of the previous models. The switching mechanism at the lower boundary (cf. Plumb, 1977, 1984) is slightly different from that by Plumb. The switching mechanism does not occur at the lower boundary but at the interior region. The present model doesn't need the viscous tropopause as mentioned by $D$, because we use the constant and small vertical eddy viscosity (see also $P B$ ). This result suggests that the small momentum diffusion in the lower stratosphere is sufficient and Plumb's (1977) estimate of diffusion of the easterly is too large.

The switching from westerly to easterly is slower than that from easterly to westerly in the lower layer. This result has not been obtained in 1 -dimensional model and is consistent with the observation (cf. Naujokat, 1986). This feature is also shown in Fig. 2 which shows the vertical profiles of time variation of the mean zonal wind at $y=150 \mathrm{~km}$ from $t=1000$ days to $t=1600$ days (about 1 cycle). This feature is also seen in the 2 -dimensional models of $P B$ and $D$.

Fig. 3 shows the latitude-height sections of mean zonal wind, temperature and vertical velocity at $t=1000$ days. This time corresponds

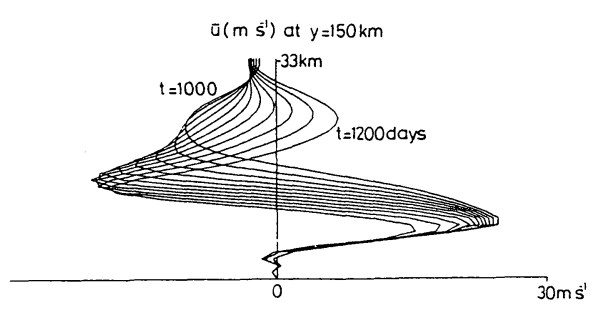

a

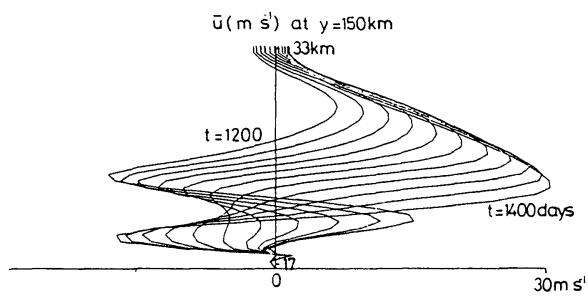

b

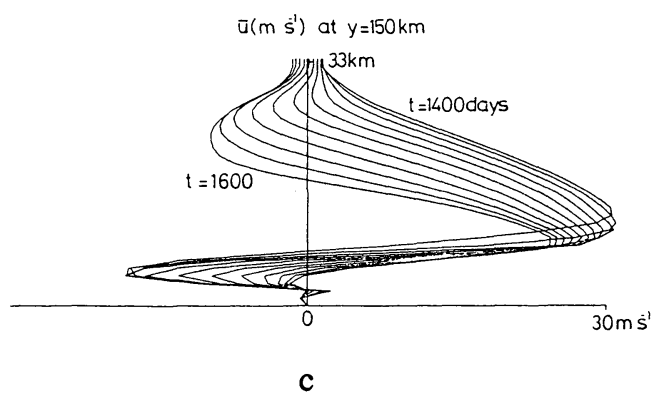

Fig. 2 Vertical profiles of time evolution of the mean zonal wind at $y=150 \mathrm{~km}$ from $t=1000$ days to $t=$ 1600 days.
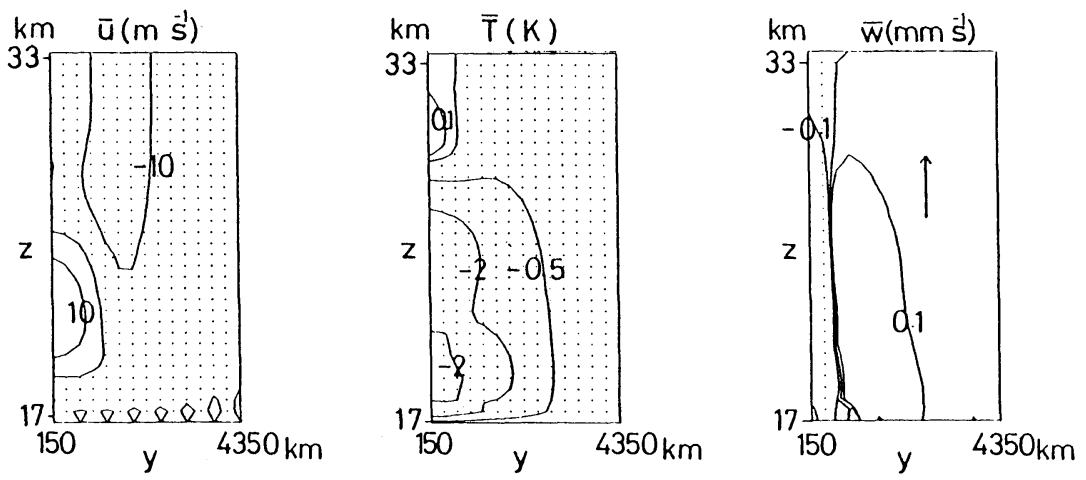

Fig. 3 Latitude-height sections of the mean zonal wind, temperature and vertical wind at $t=1000$ days. 
to the easterly wind in the upper layer and the westerly in the lower layer over the equator. The easterly wind region is wide. This meridional structure is quite different from that by $P B$ but similar to that by $D$. This is due to the choice of the phase velocity and zonal wave number of the forced waves. The meridional scale of the mixed Rossby-gravity wave is longer than that of the Kelvin wave in the present model and $D$, and vice versa in $P B$. There is cooling in the easterly shear region over the equator. This result is explained by the thermal wind balance. The maximum magnitude of the zonal mean temperature is $-3 \mathrm{~K}$ over the equator. This value is nearly equal to that by the observation (cf. Nastrom and Belmont, 1975: Hamilton, 1984; see also $P B$ ). There is the downward motion over the equator.

Fig. 4 shows the vertical profiles of the zonal mean wind forcing term $-\frac{\partial}{\partial y}(\overline{u v})-\frac{1}{\rho} \frac{\partial}{\partial z}(\rho \overline{u w})$

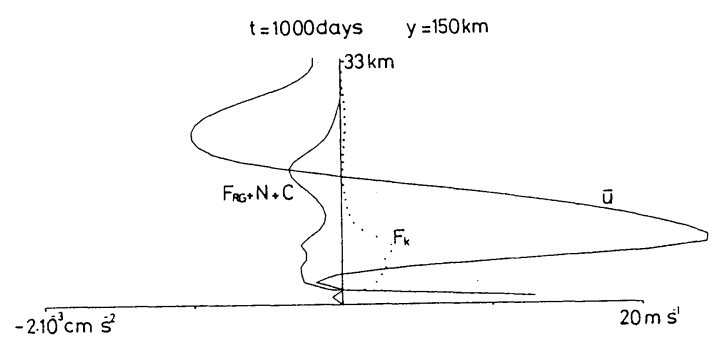

Fig. 4 Vertical profiles of zonal mean wind forcing by the Kelvin wave (denoted by $F_{k}$ ), that by the mixed Rossby-gravity wave, nonlinear advection term and Coriolis term (denoted by $F_{R G}, N$ and $C$ ) near the equator $(y=150 \mathrm{~km})$ at $t=1000$ days. by Kelvin wave (denoted by $F_{k}$ ), that by mixed Rossby-gravity wave (denoted by $F_{R G}$ ), nonlinear advection term (denoted by $N$ ) and the Coriolis term (denoted by $C$ ) in eq. $(2-6)$ at $t=1000$ days. It is noted that the nonlinear advection term and the Coriolis term cannot be separated into respective parts due to each wave. But the secondary zonal mean circulation due to Kelvin wave is small because of $v \sim 0$ for the wave (cf. Takahashi and Uryu, 1981). So it is considered that the Coriolis term and the nonlinear advection term is mainly produced by the mixed Rossby-gravity wave in the present model. Therefore we combine $F_{R G}, N$ and $C$ in Fig. 4.

This figure shows that $F_{k}$ produces westerly in the lower layer and $F_{R G}+C+N$ produce easterly in the upper layer over the equator. The dominant term of the $F_{R G}+N^{*}+C$ in the upper layer (lower layer) is $N\left(F_{R G}\right)$ term, although $N$ almost balances to $F_{R G}$. The magnitude of $F_{k}$ is slightly larger than that of $F_{R G}+N+C$ in the lower layer.

Fig. 5 shows the latitude-height sections of mean zonal wind, temperature and vertical velocity at $t=1300$ days. This time corresponds to the westerly shear in the middle layer over the equator. It is noted that the westerly region is very narrow. Therefore it spreads meridionally during downward propagation (see Fig. 3). This result is consistent with the Hamilton's analysis that the westerly acceleration is very narrow at the initial onset of the westerly (cf. Hamilton, 1984). This feature has not been simulated in previous models. This result is explained by the
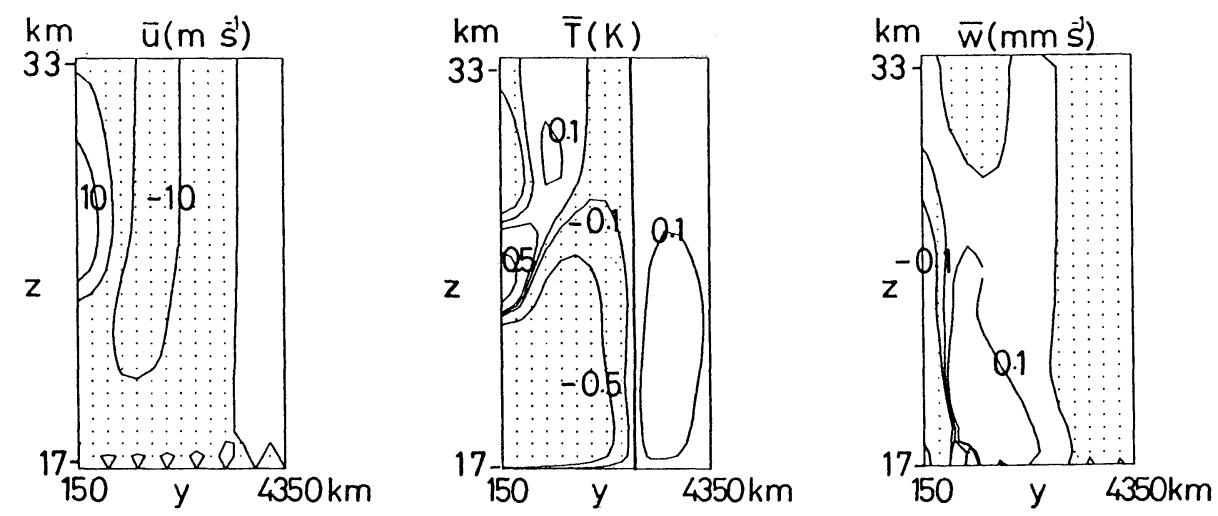

Fig. 5 Same as Fig. 3 but for $t=1300$ days. 


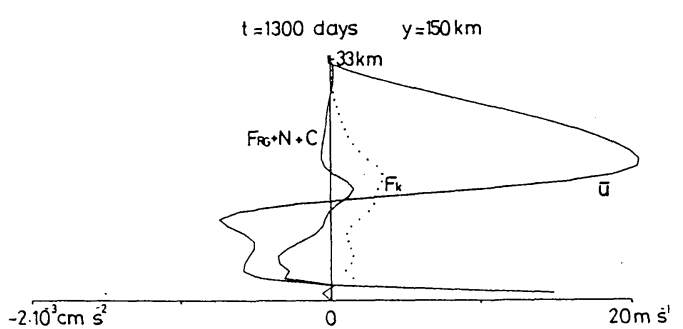

Fig. 6 Same as Fig. 4 but for $t=1300$ days. stronger easterly wind in the upper layer than that in the lower layer. This distribution of easterly is consistent with the observed mean wind (cf. Reed, 1966). There is the warm region in the westerly shear region over the equator. This result is also explained by the thermal wind balance. The mean vertical velocity is downward in the lower and middle layer over the equator.

Fig. 6 shows the mean zonal wind forcing term $F_{k}$ and the other forcing terms $F_{R G}+N+C$ at $t=1300$ days near the equator $(y=150 \mathrm{~km})$. It is noted that $F_{R G}+N+C$ produce the westerly acceleration as the same as $F_{k}$ in the westerly shear region. This is due to the nonlinear advection by the mean vertical velocity which is produced by the meridional heat flux due to the mixed Rossby-gravity wave. Thus, the downward propagation of the westerly wind is faster than that of the easterly in the middle layer.

The time interval of the westerly wind is longer than that of the easterly at the middle layers in Fig. 1. Correspondingly, the time averaged wind of the mean zonal wind is the westerly in the middle layer over the equator as shown in Fig. 7, which shows the latitude-height

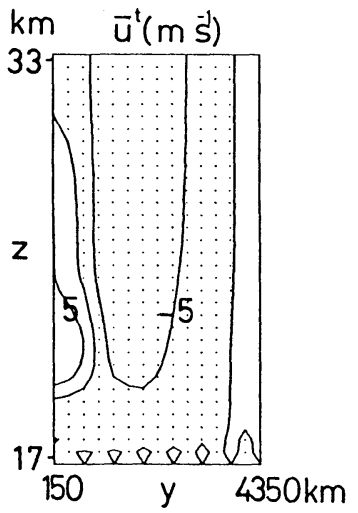

Fig. 7 Latitude-height section of the time averaged mean zonal wind.

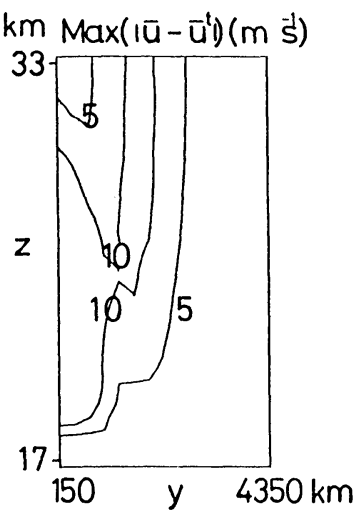

Fig. 8 Latitude-height section of the amplitude of the simulated mean zonal wind oscillation.

section of the time averaged mean zonal wind. On the other hand, the observational time mean wind in the equatorial lower stratosphere is the easterly wind (see Fig. 4 of Reed, 1966). It is noted that there is the time averaged easterly wind at the subtropical lower stratospheric region in the model. This result is similar to that of the observation, although parts of the observed easterly wind are due to the diabatic heating and/or the planetary wave coming from the extratropical troposphere.

Fig. 8 shows the latitude-height section of the amplitude of the simulated mean zonal wind oscillation. This result shows that there is the maximum amplitude of the oscillation on the equator. This is in good agreement with the observation. The meridional extent of the oscillation is about $2000 \mathrm{~km}$. This result is also in good agreement with the observation. But the maximum amplitude of zonal wind oscillation at the upper layer exists in the subtropical region. This is different from the observed QBO (see Fig. 6 of Wallace, 1973).

Fig. 9 shows the time-latitude section of the

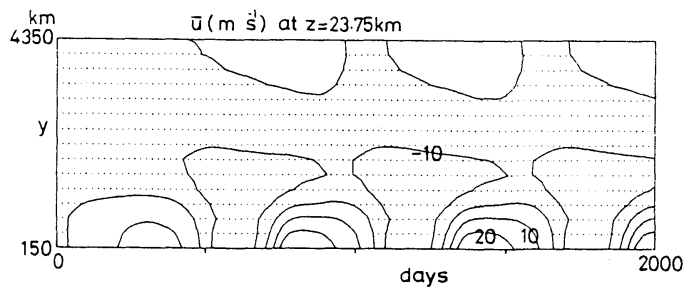

Fig. 9 Time-latitude section of the mean zonal wind at $z=23.75 \mathrm{~km}$. 
mean zonal wind at $z=23.75 \mathrm{~km}$. The westerly appears at first on the equator. On the other hand, the easterly does not. These results are very similar to those of the observed QBO (cf. Dunkerton and Delisi, 1985). The easterly wind always exists in the subtropical region. This result is also the same as that of the observation. But the time range of the westerly wind is longer than that of the easterly wind over the equator in the present model (see also Fig. 1). This is different from the observation. If the amplitude of the mixed Rossby-gravity wave at the bottom boundary is increased, the result which is similar to the observation may be obtained. But the further comparison with the observation is not useful, because other easterly acceleration mechanisms (for example, diabatic heating and/ or Rossby wave) might be also important in the real atmosphere.

\section{Examination of finite amplitude effects of equatorial wave in the model}

As mentioned in the introduction, 1-dimensional models of the QBO have been recently developed by some authors. Effects of wave transience, self-acceleration of the zonal phase velocity of the wave and wave breaking have been investigated in their models. Therefore we also examine these effects in the present 2 dimensional model.

First, we investigate the effects of wave transience and self-acceleration. Fig. 10a shows the time evolution of the mean zonal wind, the zonal phase velocity of Kelvin wave (denoted by $c_{k}$ ) and the zonal velocity amplitude of the Kelvin wave from $t=1600$ days to $t=1800$ days at $y=$ $150 \mathrm{~km}$ and $z=23.75 \mathrm{~km}$. Fig. $10 \mathrm{~b}$ also shows the time evolution of the phase velocity of mixed Rossby-gravity wave (denoted by $c_{R G}$ ) and the meridional velocity amplitude of the mixed Rossby-gravity wave in the same times at the equator and $z=23.75 \mathrm{~km}$.

The zonal phase velocity of the wave is calculated by using the following method. The complex wave amplitude is written as

$$
A e^{i \theta}
$$

where $A$ is the amplitude and $\theta$ is the phase of the wave at a fixed point. We assume

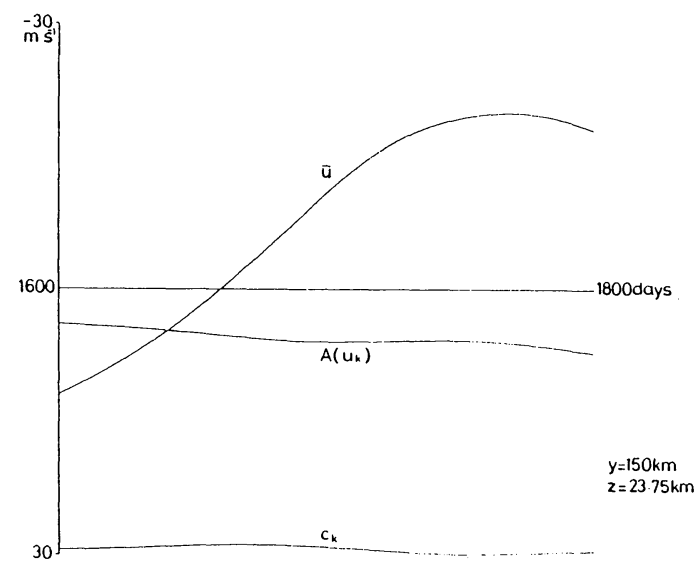

a

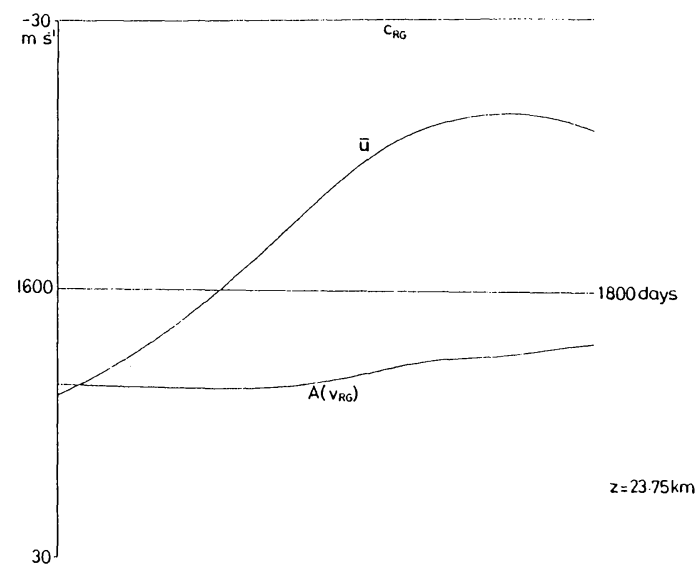

b

Fig. 10 Time evolution of the mean zonal wind, the zonal phase velocity and the amplitude of the wave from $t=1600$ days to $t=1800$ days at $z=23.75 \mathrm{~km}$. (a) is the Kelvin wave zonal wind at $y=150 \mathrm{~km}$, (b) is the meridional wind component of the mixed Rossby-gravity wave at the equator.

$$
e^{i \theta}=e^{-i k c t},
$$

where $k$ is the zonal wavenumber and $c$ is the zonal phase velocity of the wave. Using eq. (4-2), we can write down as

$$
e^{i\left(\theta_{1}-\theta_{2}\right)}=e^{-i k c\left(t_{1}-t_{2}\right)},
$$

for some arbitary time $t_{1}$ and $t_{2} . \theta_{1}$ and $\theta_{2}$ are the phases corresponding to the time $t_{1}$ and $t_{2}$, respectively. From (4-3), we can determine the phase velocity of each time interval. 


$$
c=-\frac{\left(\theta_{1}-\theta_{2}\right)}{\left(t_{1}-t_{2}\right) k} .
$$

We choose $t_{2}-t_{1}=0.5$ days in the present calculation.

It is noted that the temporal change of the zonal phase velocity of the each wave is very small in spite of the large change of the mean zonal velocity. This result is quite different from that by Tanaka and Yoshizawa (1985). This result might be due to the 2 -dimensionality of the present model.

It is also noted that the temporal change of the amplitudes of the two waves is rather large. This result shows that wave transience is crucial to the QBO. This result supports the result by Dunkerton (1981).

Second, we examine the effect of wave breaking to the QBO in the present model. Fig. 11a shows the vertical profiles of amplitude and phase of the zonal velocity component of the Kelvin wave at $t=1000$ days near the equator $(y=150 \mathrm{~km})$. The maximum amplitude is about $10 \mathrm{~m} \mathrm{~s}^{-1}$. The magnitude is in good agreement with that obtained by Wallace and Kousky

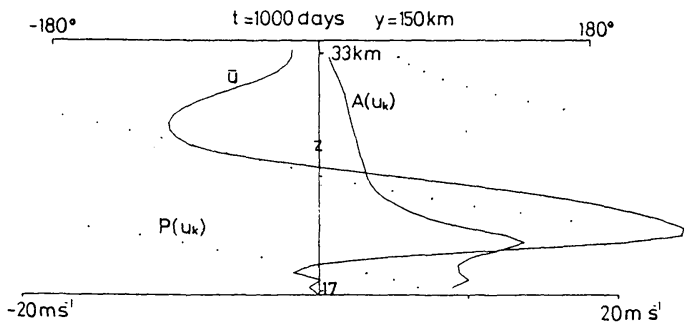

Fig. 11a Vertical profiles of amplitude (real line) and phase (dotted line) of the zonal wind component of the Kelvin wave at $t=1000$ days near the equator $(y=150 \mathrm{~km})$. The mean zonal wind is also shown for reference.

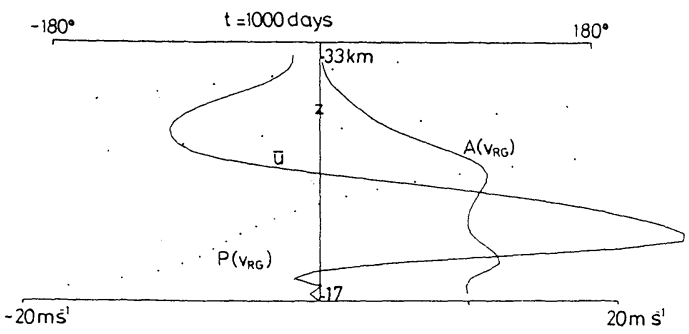

Fig. 11b Same as Fig. 11a but for the meridional wind component of the mixed Rossby-gravity wave at the equator.
(1968) observationally. This result shows that the wave breaking occurs in the lower layer. This is because the condition of the wave breaking of the Kelvin wave is $\hat{c} \sim|u|$ (see Appendix).

Fig. $11 \mathrm{~b}$ shows the vertical profiles of amplitude and phase of the meridional velocity component of the mixed Rossby-gravity wave at $t=$ 1000 days over the equator. The maximum amplitude of the meridional velocity component is nearly $10 \mathrm{~m} \mathrm{~s}^{-1}$, and the amplitude of the zonal velocity of the mixed Rossby-gravity wave is very small near the equator. This result suggests that the mixed Rossby-gravity wave breaking does not occur at this time (see Appendix). These results suggest that the wave breaking is important, to some extent, to the QBO. As shown in the figures, the phase of the wave is sufficiently resolved. This result shows that the vertical grid size $\Delta z=500 \mathrm{~m}$ is sufficient.

\section{Dependence of the results on the dissipation}

In this section, the dependence of the results on the magnitude of the dissipation coefficients is examined.

At first, we use the following large dissipation coefficients,

$$
\begin{aligned}
& \alpha= \alpha_{N}=10^{-6} \\
&+1 \times 10^{-5} \cdot \exp ((z-33 \mathrm{~km}) / 2 \mathrm{~km}) \mathrm{s}^{-1}, \\
& \nu=\kappa=0.1 \mathrm{~m}^{2} \mathrm{~s}^{-1} .
\end{aligned}
$$

It is noted that the bottom boundary forcings of the waves and other parameters are the same as those in sections 3 and 4 .

Fig. 12 shows the time-height section of the mean zonal wind at $y=150 \mathrm{~km}$. Initial condition is $\bar{u}=0$. As the time tends to infinity, a steady state solution is obtained. Present steady state solution corresponds to that obtained by Plumb and McEwan (1978) under the condition of large dissipation coefficient. It is noted that the magnitude of the mean zonal wind is very small. It is further noted that this steady solution is of different type from that obtained by Plumb (1977) (Fig. 4a in his paper), in which the steady solution is obtained under the condition of $\nu=0$.

We have conducted numerical experiments with different initial conditions of $\bar{u}$, but all 


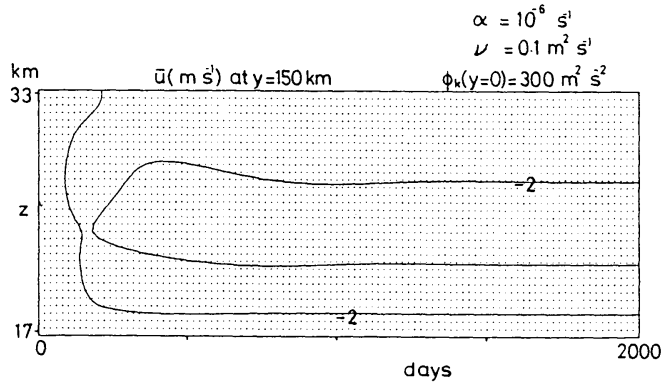

Fig. 12 Time-height section of the mean zonal wind at $y=150 \mathrm{~km}$ in case of large dissipation coefficients.

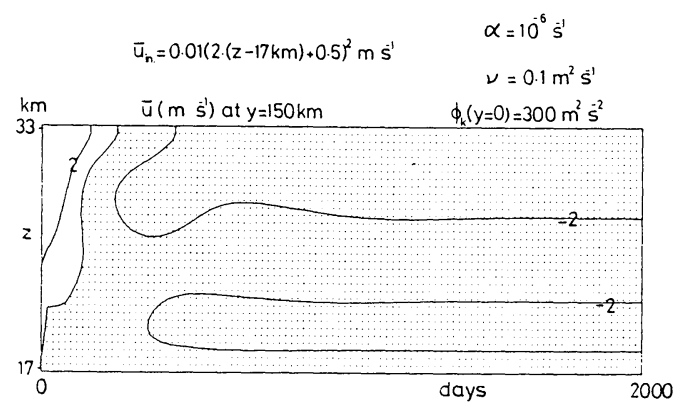

Fig. 13 Same as Fig. 12 but for a different initial condition.

results converge to the same steady state solution as the time goes to infinity in spite of the nonlinear equation system. Fig. 13 shows an example whose initial condition is $\bar{u}=0.01(2(z-17 \mathrm{~km})$ $+0.5)^{2} \mathrm{~m} \mathrm{~s}^{-1}$. The magnitude of the initial mean zonal velocity near the top boundary $(z=33 \mathrm{~km})$ is about $10 \mathrm{~m} \mathrm{~s}^{-1}$. The same equilibrium solution is obtained. The results are also the same in cases of the more faster initial velocity (about $\pm 50 \mathrm{~m} \mathrm{~s}^{-1}$ near the top boundary) of the mean zonal wind. From these numerical experiments, it seems that multiple equilibrium does not exist but only one equilibrium solution exists at least in the present parameters. This result may be due to the smallness of the amplitude of the mean wind. But this result is not conclusive, because we do not solve the steady state equation directly.

Figs. 14a, b show the vertical distributions of amplitude and phase of velocity components of the Kelvin wave and the mixed Rossby-gravity wave at $t=2000$ days (almost steady state) near the equator in the above case. Fig. 15 shows the vertical profiles of the mean zonal wind acceleration due to Kelvin wave and mixed Rossby-

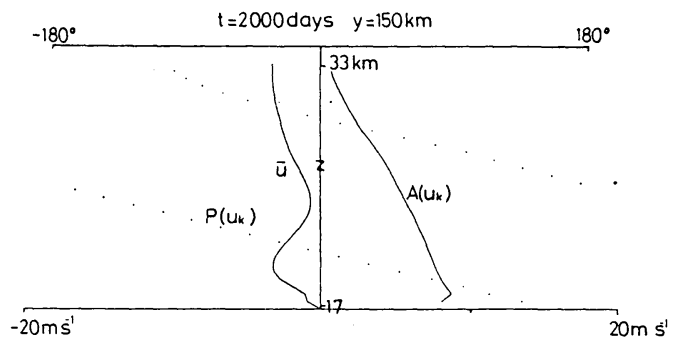

a

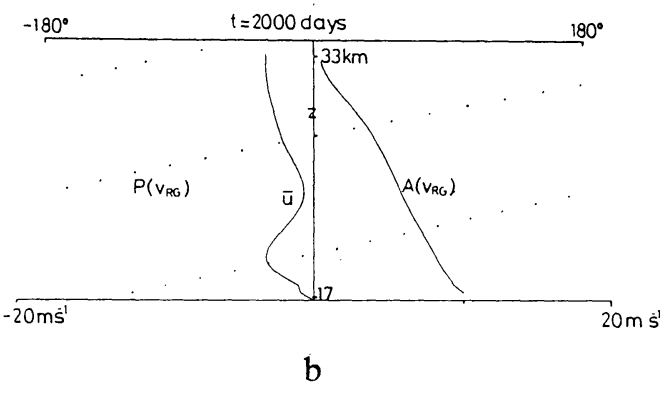

Fig. 14 Vertical distributions of (a) the mean zonal velocity, wave amplitude and phase of zonal wind component of the Kelvin wave at $y=150 \mathrm{~km}$ and (b) wave amplitude and phase of meridional wind component of the mixed Rossby-gravity wave at the equator.

gravity wave at $t=2000$ days near the equator. The magnitudes of waves and the acceleration due to the waves are slightly smaller than those of the oscillatory case. But the acceleration due to the Kelvin wave is nearly the same as that due to the mixed Rossby-gravity wave in all levels since a steady state is attained. Further, the magnitudes of the waves and the acceleration gradually decreases with height. Thus, the total acceleration is much smaller than that of the oscillatory case, and a steady state solution is obtained in the present case.

Next we impose the following smaller dissipa-

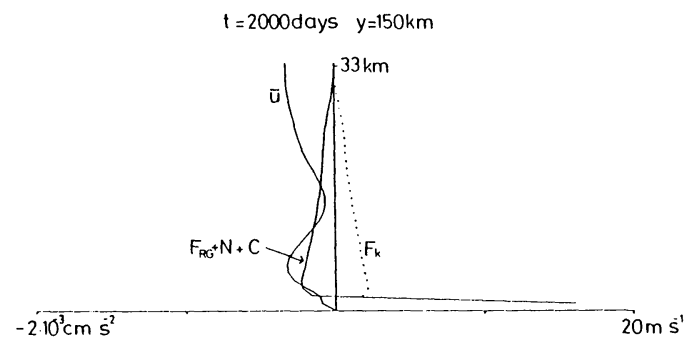

Fig. 15 Vertical profiles of the mean zonal wind acceleration at $t=2000$ days in Fig. 12 . 


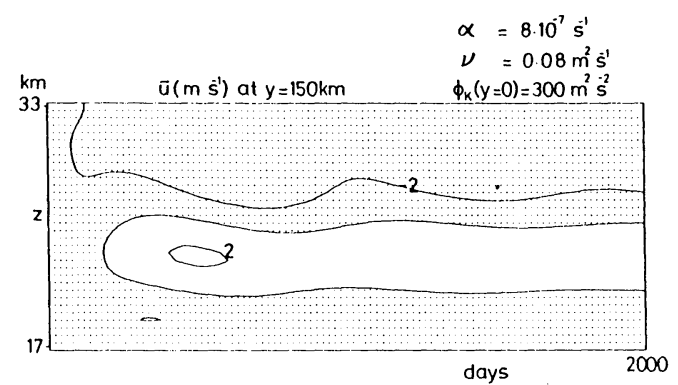

a

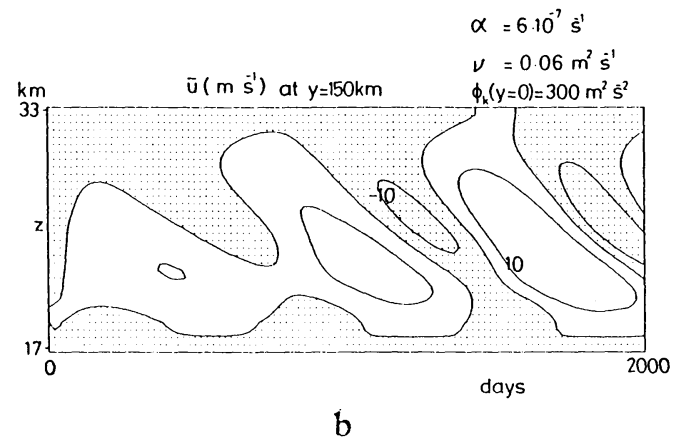

Fig. 16 Same as Fig. 12 but for the smaller dissipation coefficients.

tion coefficients,

$$
\begin{aligned}
\alpha= & \alpha_{N}=8 \times 10^{-7} \\
& +1 \times 10^{-5} \cdot \exp ((z-33 \mathrm{~km}) / 2 \mathrm{~km}) \mathrm{s}^{-1},
\end{aligned}
$$

$\nu=\kappa=0.08 \mathrm{~m}^{2} \mathrm{~s}^{-1}$.

The time evolution of the mean zonal wind near the equator is obtained as shown in Fig. 16a. A very small amplitude oscillation with period of about 1000 days exists. It is noted that the period is much longer than that of the oscillation in section 3 . Initial condition is motionless at $t=$ 0 day.

Finally we use the following dissipation coefficients,

$$
\begin{aligned}
\alpha= & \alpha_{N}=6 \times 10^{-7} \\
& +1 \times 10^{-5} \cdot \exp ((z-33 \mathrm{~km}) / 2 \mathrm{~km}) \mathrm{s}^{-1},
\end{aligned}
$$

$\nu=\kappa=0.06 \mathrm{~m}^{2} \mathrm{~s}^{-1}$.
Note that these values of dissipation coefficients are nearly equal to those in section 3 . A realistic oscillation with large amplitude and shorter period of about 800 days is obtained (Fig. 16b). The amplitude of the oscillation is about $10 \mathrm{~m} \mathrm{~s}^{-1}$. It is noted that the transition from the steady state solution to the oscillatory solution is not drastic, but smooth.

\section{Concluding remarks}

Using a 2-dimensional numerical model, we have conducted numerical experiments of the QBO. Main results are as follows.

We obtained an oscillation with period of about 600 days whose structures are very similar to those of the observed QBO. For example, the faster downward propagation of the westerly wind than that of the easterly was obtained. The westerly wind appears at first on the equator but the easterly spreads from the mid-latitude region. The meridional extent of the westerly wind at the initial onset of the westerly in the upper layer is very narrow. This feature was first obtained in the present model. Further, it was shown that the viscous tropopause is not needed to switch the mean zonal wind at the lower boundary. But the time averaged zonal mean wind in the middle layer on the equator is the westerly in the model. On the other hand, the time averaged zonal mean wind is the easterly in the observation.

We analyzed the roles of wave transience, the self-acceleration of the zonal phase velocity of the wave and the wave breaking in the present model. The effects except wave self-acceleration are crucial to the QBO in the present model.

We also examined the dependence of the results on the magnitude of the dissipation coefficients in section 5 . When we use the larger dissipation, a steady state solution is obtained. But we did not still obtain multiple equilibrium.

It is often pointed out that the easterly acceleration by the mixed Rossby-gravity wave is deficient to realize the QBO in the real atmosphere and other kinds of easterly acceleration mechanism (for example, $n=1$ equatorial Rossby wave) are needed (cf. Lindzen and Tsay, 1974; Andrew and McIntyre, 1976). This problem will be studied in the next companion paper (part II). 


\section{Acknowledgments}

The author wishes to express his thanks to Drs. S. Miyahara, H. Tanaka and N. Yoshizawa for their careful reading of the manuscript and helpful comments. Discussions with Profs. M. Fujiwara and M. Uryu are very helpful. The numerical computations were performed by use of FACOM V-100 computer at Kyushu University.

\section{Appendix}

Approximate relations for the condition of the wave breaking

(1) Case of convective instability of the Kelvin wave

For simplicity, we consider a Boussinesq fluid. The condition for convective instability is as follows (cf. Lindzen, 1981),

$$
\left|\frac{\partial^{2} \phi}{\partial z^{2}}\right| \sim N^{2}
$$

We assume a wave solution as $\phi \sim e^{i m z}$ ( $\mathrm{m}$ is the vertical wavenumber). Then (A-1) becomes

$$
m^{2}|\phi| \sim N^{2} .
$$

From the wave momentum equation in the zonal direction, we can obtain the following equation,

$$
\hat{c} u \sim \phi,
$$

where $\hat{c}$ is the doppler shifted phase velocity. From (A-2) and (A-3), we obtain

$$
m^{2}|\hat{c} u| \sim N^{2}
$$

Finally we use the dispersion relation of the Kelvin wave as

$$
\hat{c}=N / m \text {. }
$$

Then from (A-4) and (A-5), we can get

$$
|u| \sim \hat{c}
$$

This formula is a relation for the condition of the convective instability of the Kelvin wave.

(2) Case of the mixed Rossby-gravity wave

The physical mechanism of the breaking is not clearly understood for the mixed Rossby- gravity wave (cf. Tanaka and Yoshizawa, 1987). In the following discussion, we consider the wave breaking in special cases.

(i) convective instability

In case of the breaking due to the convective instability, (A-2) is also satisfied,

$$
m^{2}|\phi| \sim N^{2} .
$$

For the mixed Rossby-gravity wave, the following equation is obtained over the equator $(u \sim 0)$,

$$
|L \hat{\omega} v| \sim|\phi|,
$$

where $L=\sqrt{2 N / \beta l}$ is the meridional scale of the mixed Rossby-gravity wave.

From the above equations, the following equation is obtained,

$$
|v| \sim \frac{N^{2}}{m^{2}} \frac{1}{L \hat{\omega}} .
$$

This approximate relation is the condition of the convective breaking of the mixed Rossbygravity wave over the equator. This relation gives $|v| \sim 30(9) \mathrm{m} \mathrm{s}^{-1}$ when $\hat{c}_{R G}=-30(-20) \mathrm{m} \mathrm{s}^{-1}$. (ii) barotropic instability

The condition of the breaking due to the barotropic instability for the mixed Rossbygravity wave may be written as follows (cf. Lindzen and Schoeberl, 1982),

$$
\left|\frac{\partial q}{\partial y}\right| \sim \beta
$$

where $q$ is the vorticity of the disturbance. $q=\frac{\partial v}{\partial x}-\frac{\partial u}{\partial y} \sim \frac{\partial v}{\partial x}$ for the mixed Rossbygravity wave over the equator. Then (A-10) is rewritten as

$$
\frac{k}{L}|v| \sim \beta \text {. }
$$

This equation gives $|v| \sim 60$ (35) $\mathrm{m} \mathrm{s}^{-1}$ when $\hat{c}_{R G}=-30(-20) \mathrm{m} \mathrm{s}^{-1}$.

\section{References}

Andrews, D.G. and M.E. McIntyre, 1976: Planetary waves in horizontal and vertical shear: The generalized Eliassen-Palm relation and the mean zonal acceleration. J. Atmos. Sci., 33, 2031-2048. 
Dickinson, R.E., 1973: Method of parameterization for infrared cooling between altitudes of 30 and 70 kilometers. J. Geophys. Res. 78, 4451-4457.

Dunkerton, T.J., 1981: Wave transience in a compressible atmosphere. part II: Transient equatorial waves in the quasi-biennial oscillation. J. Atmos. Sci., 38, 298-307.

298-1985: A two-dimensional model of the quasi-biennial oscillation. J. Atmos. Sci., 42, 1151 1160.

- and D.P. Delisi, 1985: Climatology of the equatorial lower stratosphere. J. Atmos. Sci., 42, $376-396$.

Hamilton, K., 1984: Mean wind evolution through the quasi-biennial cycle in the tropical lower stratosphere. J. Atmos. Sci., 41, 2113-2125.

Holton, J.R., 1975: The Dynamic Meteorology of the Stratosphere and Mesosphere. Meteor. Monogr., No. 37, Amer. Meteor. Soc., 218pp.

, 1979: Equatorial wave-mean flow interaction: A numerical study of the role of latitudinal shear. J. Atmos. Sci., 36, 1030-1040.

and R.S. Lindzen, 1972: An updated theory for the quasi-biennial cycle of the tropical stratosphere. J. Atmos. Sci., 29, 1076-1080.

Lindzen, R.S., 1981: Turbulence and stress owing to gravity wave and tidal breakdown.J. Geophys. Res., 86, 9707-9714.

and J.R. Holton, 1968: A theory of the quasibiennial oscillation. J. Atmos. Sci., 25, 1095-1107.

and M.R. Schoeberl, 1982: A note on the limits of Rossby wave amplitudes. J. Atmos. Sci., 39, $1171-1174$.

and C.-Y. Tsay, 1975: Wave structure of the tropical stratosphere over the Marshall islands area during 1 April-1 July 1958. J. Atmos. Sci., 32, 2008-2021.

Mahlman, J.D. and L.J. Umscheid, 1984: Dynamics of the middle atmosphere: Successes and problems of the GFDL "SKYHI" general "circulation model. Dynamics of the Middle Atmosphere (J.R. Holton and T. Matsuno eds.), Terra Scientific Publishing Company, pp. 501-525.

Nastrom, G.D. and A.D. Belmont, 1975: Periodic variations in stratospheric-mesospheric temperature from $20-65 \mathrm{~km}$ at $80^{\circ} \mathrm{N}$ to $30^{\circ} \mathrm{S}$. J. Atmos. Sci., 32,
$17.15-1722$.

Naujokat, B., 1986: An update of the observed quasibiennial oscillation of the stratospheric winds over the tropics. J. Atmos. Sci., 43, 1873-1877.

Plumb, R.A., 1977: The interaction of two internal waves with the mean flow: Implications for the theory of the quasi-biennial oscillation, J. Atmos. Sci., 34, 1847-1858.

- 1984: The quasi-biennial oscillation. Dynamics of the Middle Atmosphere (J.R. Holton and T. Matsuno eds.), Terra Scientific Publishing Company, pp. $217-251$.

and A.D. McEwan, 1978: The instability of a forced standing wave in a viscous stratified fluid: A laboratory analogue of the quasi-biennial oscillation. J. Atmos. Sci., 35, 1827-1839.

and R.C. Bell, 1982: A model of the quasibiennial oscillation on an equatorial beta-plane. Quart. J. Roy. Meteor. Soc., 108, 335-352.

Reed, R.J., 1966: Zonal wind behavior in the equatorial stratosphere and lower mesosphere. J. Geophys. Res., 71, 4223-4233.

, W.J. Campbell, L.A. Rasmussen and D.G. Rogers, 1961: Evidence of a downward-propagating, annual wind reversal in the equatorial stratosphere. J. Geophys. Res., 66, 813-818.

Takahashi, M. and M. Uryu, 1981: The Lagrangian-mean motions forced by steady, dissipating equatorial waves: Part I. J. Meteor. Soc. Japan, 59, 781-800.

Tanaka, H. and N. Yoshizawa, 1985: Quasi-biennial oscillation and its analog under the assumption of wave self-acceleration. J. Atmos. Sci., 42, 23502359.

- 1987: A slowly-varing model of QBO involving effects of transience, self-acceleration and saturation of equatorial waves. J. Atmos. Sci., 44, 1427-1436.

Wallace, J.M., 1973: General circulation of the tropical lower stratosphere. Rev. Geophys. Space Phys., 11, 191-222.

and V.E. Kousky, 1968: Observational evidence of Kelvin waves in the tropical stratosphere. $J$. Atmos. Sci., 25, 900-907.

Yanai, M. and T. Maruyama, 1966: Stratospheric wave disturbances propagating over the equatorial Pacific. J. Meteor. Soc. Japan, 44, 291-294. 


\section{準 2 年振䃼の 2 次元モデル：第 1 部 \\ 高 橋 正 明}

(九州大学理学部物理学教室)

2 次元モデルを使って準 2 年振動（ＱＢＯ）の数值実験を行い, 周期約 600 日の振動を得ることがで きた。モデルで再現した振動は，多くの点で観測されている QBO と非常によくにている:

（1）西風が東風より速く下降すること。

（2）西風は赤道上に最初あらわれ中緯度の方に拡がる。一方，東風は中緯度の方から低緯度の方に 拡がってくること。

(3) 西風が上層で出現するとき，西風の子午面方向の拡がりが非常に狭いこと。

波の transience, 自己加速による位相速度の変化及び波の breaking の効果を解析した。このモデル では，これらの効果は波の自己加速の効果を除いてQBO のメカニズムにとって重要であることがわか つた。

散冕係数が大きいとき，初期条件を幾つか変えて実験を行ったが，常に同じ定常解しか得られなかっ た。 